\title{
Determination of peptaibol trace amounts in marine sediments by liquid chromatography/electrospray ionization-ion trap-mass spectrometry
}

\author{
Laurence POIRIER ${ }^{1^{\star}}$, Jean-Claude AMIARD ${ }^{1}$, Florence MONDEGUER ${ }^{2}$, Françoise \\ QUINIOU $^{3}$, Nicolas RUIZ ${ }^{1}$, Yves François POUCHUS ${ }^{1}$, Monique MONTAGU ${ }^{1}$
}

\footnotetext{
${ }^{1}$ Université de Nantes, Nantes Atlantique Universités, SMAB, EA2160, Faculté de pharmacie, 1 rue G. Veil - BP 53508, Nantes, F-44000 France

IFREMER-DEL/PN, Centre de Nantes, 1 Rue de l'Île d'Yeu Nantes - BP 21105, 44311 Nantes Cedex 3, France

${ }^{3}$ IFREMER- BE/EX, Centre de Brest - BP 70, 29280 Plouzané, France

* Corresponding author: laurence.poirier@univ-nantes.fr
}

\begin{abstract}
:
Extraction followed by reverse phase liquid chromatography (LC)/electrospray ionization-ion trap-mass spectrometry (ESI-IT-MS) analysis has been successfully developed for the determination of peptaibols, fungal toxic metabolites, in marine sediments. Spiking experiments showed that the mean recovery of target compounds exceeded $85 \%$ at a spiking level of $10 \mathrm{ng} / \mathrm{g}$ of sediment (wet weight). Detection and quantification limits were 250 and $830 \mathrm{pg} / \mathrm{g}$ of sediment, respectively. The method developed constituted the first sensitive assay for quantification of peptaibol trace amounts in a natural environment. A concentration of $5 \mathrm{ng} / \mathrm{g}$ in sediment samples collected from Fier d'Ars was found.
\end{abstract}

Keywords: Fungal peptide metabolites; Trichoderma sp.; Marine fungal contamination; Electrospray ionization-ion trap-mass spectrometry (ESI-IT-MS); Matrix matched calibration 
Fungal production of mycotoxins in the marine environment is proposed as a possible cause for episodes of unexplained toxicity observed in shellfish populations during the last decade. Within this framework, numerous strains of toxigenic saprophytic fungi were isolated from shellfish, sediment and seawater samples collected in shellfish farming areas [1]. Among them, different strains of Trichoderma sp., grown in marine-like culture conditions, produced peptaibols, peptidic metabolites, which are toxic for different larval models (diptera or crustacean larvae) [2].

Peptaibols constitute a constantly growing family of linear peptide antibiotics of fungal origin. They are characterized by a molecular mass from 500 to $2200 \mathrm{u}$, an acetyled Nterminus, a C-terminus amino alcohol and a high content of a non proteinogenic amino acid, $\alpha$-aminoisobutyric acid (Aib or U) [3]. Peptaibols are exclusively produced by filamentous fungi mainly belonging to the genera Trichoderma, Acremonium, Paecilomyces, Emericellopsis and Gliocladium. They have been classified into subfamilies according to their amino acid chain lengths (ranging from 5 to 20 residues) and their chemical characteristics [4]. These fungal metabolites exhibit a variety of biological activities resulting from their membrane-modifying and pore-forming properties. Thus antibacterial, antifungal and occasionally antiviral and antiparasitic activities have been reported [5-8].

A previous experimental contamination has shown that peptaibols can be accumulated in filter-feeder molluscs (Mytilus edulis) when present in sea-water as soluble compounds [9]. The presence of such compounds in the marine environment could lead to health risks for shellfish and their consumers. Different peptaibols were recently detected in sediments in a marine area devoted to shellfish farming (Fier d'Ars, Atlantic coast, France) [10]. These sediment samples displayed high toxicity for mussel larvae in the absence of significant contaminations (metals, PCBs, HAPs, pesticides, antibiotics) or eutrophication [11]. Developing analytical methods allowing the precise determination of these fungal metabolites in the marine environment is therefore of great interest in order to establish a causal relationship between peptaibol concentrations and biological effects. Certain methods, that use radioactivity or capillary electrophoresis coupled with UV and ESI-TOF-MS, have already been described for the quantification of peptaibols isolated from fungal cultures $[12,13]$. However, they are not sensitive enough for determining trace amounts. The aim of this work is to develop a process for extracting peptaibols from marine sediment matrices and a sensitive assay for the determination of trace amounts by using LC/ESI-IT-MS. The method developed focuses on long-sequence peptaibols, including 18 to 20 amino acid residues, because of their high bioactivity [6] and their predominance in peptaibol family [14].

\section{Experimental}

\subsection{Chemicals}


Methanol and dichloromethane were purchased from Carlo Erba (Val de Reuil, France) and distilled before use. Ethanol was purchased from APC (Aubervilliers, France). Trifluoroacetic acid (TFA) was obtained from Fluka Chemical (Buchs, Switzerland), hydrochloric acid from Acros organics (Geel, Belgium) and acetic acid from Sigma Aldrich (Saint-Quentin Fallavier, France). For mass spectrometry analysis, HPLC-grade methanol was obtained from Baker (Deventer, Holland). Water was purified to HPLC-grade quality with a Millipore-Q RG ultrapure water system from Millipore (Milford, CT, USA). Alamethicin F50 was obtained from Sigma Aldrich (Ref. A4665).

\subsection{Sediment samples}

Sediment samples used for optimizing extraction and purification procedures were collected from La Rochelle (France) in January 2000. They were transported from the site to the laboratory in isothermic containers and frozen at $-20^{\circ} \mathrm{C}$.

Sediment samples used to estimate environmental contamination were collected from different sites on the French Atlantic coast. Surface sediment samples (oxic fraction, $1^{\text {st }} \mathrm{cm}$ ) were collected from four sites: the Bay of Marennes-Oléron (45 $55^{\circ} \mathrm{N} 1^{\circ} 13^{\prime} \mathrm{W}$ ), Auray

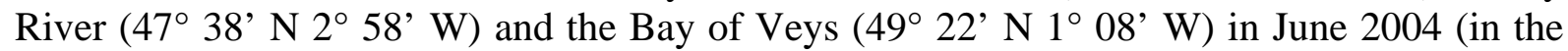
framework of the French program "MOREST"), and from Fier d'Ars (Ré Island - $46^{\circ} 13^{\prime} \mathrm{N}$ $1^{\circ} 29^{\prime} \mathrm{W}$ ) in March 2006. All the samples were transported from the site to the laboratory in isothermic containers and frozen at $-20^{\circ} \mathrm{C}$ until analysis. Each sample (approximately $10 \mathrm{~g}$ wet weight) was subjected to extraction, purification and LC/ESI-IT-MS analysis.

\subsection{Optimization of the extraction procedure}

The efficiency of the extraction procedure was checked by recovery experiments. The nature of the extraction solvents was the decisive parameter for which optimization was required. Approximately $10 \mathrm{~g}$ wet weight (ww) of sediments were spiked with $100 \mathrm{ng}$ of alamethicin F50 and extracted with $3 \times 25 \mathrm{~mL}$ of different organic solvents. According to the preliminary experiments, five different mixtures of solvents were selected for definitive tests: (a) dichloromethane/methanol (1:1, v/v), (b) methanol/TFA 0.1\% (v/v), (c) ethanol/acetic acid $1 \%(\mathrm{v} / \mathrm{v}),(\mathrm{d})$ acetone/acetic acid $1 \%(\mathrm{v} / \mathrm{v})$ and (e) acetone/hydrochloric acid $0.02 \%(\mathrm{v} / \mathrm{v})$. At each extraction step, the sample was sonicated for $15 \mathrm{~min}$ and centrifuged at $700 \mathrm{~g}$ for $5 \mathrm{~min}$. Two procedures were used in order to eliminate salts. The supernatants obtained with mixtures (a), (b) and (c) were evaporated to dryness and redissolved in $50 \mathrm{~mL}$ of dichloromethane/methanol/water (2:2:1). The aqueous phase containing salts was washed twice with dichloromethane. The organic phases were then combined and evaporated to dryness. The supernatants obtained with solvent mixtures (d) and (e) were simply filtered and evaporated to dryness (crude extracts).

\subsection{Purification of extracts}

Purification of crude extracts was performed by vacuum liquid chromatography (VLC) on a diol-silica gel column (10 x $40 \mathrm{~mm})$ (Supelco, Bellefonte, PA, USA). The column was prepared with $2 \mathrm{~g}$ of sorbent and rinsed with $10 \mathrm{~mL}$ of dichloromethane prior to sample 
loading. For this step, two deposit modes were investigated. In mode 1, the extract was redissolved and deposited with $3 \mathrm{~mL}$ of three successive solvent mixtures in the purification column: dichloromethane/ethanol (100:0, 90:10 and 50:50, v/v). Mode 2 corresponded to a dry deposit. The crude extract was dissolved in $10 \mathrm{~mL}$ of dichloromethane/ethanol mixture (50:50, v/v) and mixed with a quarter of the sorbent phase. This mixture was evaporated to dryness and loaded in the column. Elution was performed with $40 \mathrm{~mL}$ of successive dichloromethane/ethanol mixtures (100:0, 98:2, 90:10 and 50:50, v/v). The fractions obtained (A, B, C and D, respectively) were evaporated to dryness and redissolved in methanol (500 $\mu \mathrm{L})$ prior to analysis by using the hyphenated LC/MS technique.

\subsection{LC/MS analysis}

The samples were analyzed on a modular HPLC system consisting of a Spectraphysics Spectra System P2000 pump, an AS 100XR autosampler (Thermo Separation Products, San Jose, CA, USA) equipped with a Kromasil C-18 5- $\mu \mathrm{m}$ reverse-phase $2.0 \times 250 \mathrm{~mm}$ column (Interchim, Montluçon, France) heated to $40^{\circ} \mathrm{C}$ and coupled with a Finnigan Matt LCQ ${ }^{\mathrm{TM}}$ ESI-IT-mass spectrometer (Thermo Separation Products). The mobile phase consisted of a methanol/ $\mathrm{H}_{2} \mathrm{O}(85: 15, \mathrm{v} / \mathrm{v})$ mixture delivered at a constant flow rate of $0.2 \mathrm{~mL} / \mathrm{min}$ (isocratic mode). The sample injection volume was $5 \mu \mathrm{L}$. All mass analyses were performed in positive mode. To ensure optimal detection, perfusion of a methanolic solution of alamethicin F50 (50 $\mathrm{ng} / \mathrm{mL}$ ) into the flow of LC using a micrometrically automated $250-\mu \mathrm{L}$ syringe (Hamilton, Reno, NV, USA) at a flow rate of $3 \mu \mathrm{L} / \mathrm{min}$ was performed to optimize the mass spectrometer parameters. The spray voltage was set to $4.50 \mathrm{kV}$, the capillary temperature to $266^{\circ} \mathrm{C}$ and the capillary voltage to $42 \mathrm{~V}$. Nitrogen flow rates were 89 and 37 (arbitrary units), respectively, for sheath and auxiliary gas. The parameters of ion optic transmission were adjusted to $55 \mathrm{~V}$ for Tube Lens Offset, -3.50 V for Multipole 1 Offset, - 6 for Multipole 2 Offset and $400 \mathrm{~V}$ for Multipole RF Amplifier (peak to peak).

$\mathrm{MS}^{\mathrm{n}}$ spectra acquisitions were carried out with a collision energy of 32\% and an isolation width of $1 \mathrm{u}$.

All spectra acquisitions and reworks were done using LCQ Xcalibur 1.3 software (Thermo Fisher Scientific).

\subsection{Calibration and quantification}

External and matrix matched calibrations were compared. A commercial solution of alamethicin F50 was used as external standard and characterized by LC/MS ${ }^{\mathrm{n}}$ analysis. This product contains four individual components which have been identified as alamethicin F50/5, F50/6a, F50/7 and F50/8b with molecular masses of 1962, 1976, 1976 and $1990 \mathrm{u}$ respectively, according to Kirschbaum et al. [15].

The two main components, alamethicin F50/5 (m/z 1004.3, $\left.t_{R} 8.8 \mathrm{~min}\right)$ and F50/7 (m/z $1011.3, t_{R} 10.6 \mathrm{~min}$ ), which represented a constant proportion of $90.5 \%$ in the reference solution, were used for the calibration performed by using LC/ESI-IT-MS. This proportion remained constant after the extraction and purification steps. For external standardization, a calibration curve was prepared using 8 concentrations of alamethicin F50 in methanolic solution (1 to $100 \mu \mathrm{g} / \mathrm{L}$ ). To consider the matrix effects, matrix matched calibration samples 
were prepared by adding different concentrations of alamethicin F50 to sediment extracts obtained after purification. $100 \mu \mathrm{L}$ of alamethicin F50 reference solution at 12.5, 25, 50, 100 and $200 \mu \mathrm{g} / \mathrm{L}$ were added to $100 \mu \mathrm{L}$ of each purified fraction $\mathrm{C}$ and $\mathrm{D}$. LC/MS analysis of each concentration level was performed 6 times for both external and matrix matched calibrations. The accuracy and precision of the matrix matched calibration method were calculated for each concentration level.

The accuracy of the method developed was determined by the analysis of three sediment samples spiked with $100 \mathrm{ng}$ of alamethicin F50 solution. All the percentages of recovery were determined relative to the standard samples.

\subsection{Statistical treatment}

Mann Whitney U-tests were carried out to compare the percentages of recovery of alamethicin F50 and impurity masses obtained during the optimization of the extraction and purification steps. Pearson's correlation was used to test the linearity of the quantification data.

\section{Results and discussion}

\subsection{Selection of extraction conditions of peptaibols from sediments}

To achieve the efficient extraction of the target compounds, recovery experiments with alamethicin F50 spiked sediments were carried out. Five solvent mixtures were evaluated and the results are shown in Table 1. Extraction using mixtures of dichloromethane/methanol, methanol/TFA and ethanol/acetic acid did not provide satisfactory recovery of alamethicin F50, since the values were below $10 \%$. Methanol was generally used in the extraction procedures of peptaibols from fungal cultures (qualitative analysis) [16,17]. In spite of its high eluotropic strength, this solvent was not strong enough to remove peptaibols from a complex sedimentary matrix. Acetone/hydrochloric acid mixture (e) provided a higher recovery of alamethicin F50 with a mean of $64 \pm 9 \%$. Satisfactory extraction efficiency (86 \pm 20\%) was obtained using acetone/acetic acid mixture (d) (significant differences with (a), (b) and (c) at the $95 \%$ level). An additional extraction test was performed with acetone $100 \%$ and resulting in $47 \%$ recovery (results not shown), a value lower than those obtained for acidified acetone mixtures. Acid conditions were essential for the extraction of molecules of interest from sedimentary particles. The acetone/acetic acid $1 \%(\mathrm{v} / \mathrm{v})$ mixture was therefore chosen as the best solvent for further studies.

\section{TABLE 1}




\subsection{Purification of analytes}

214

The crude extracts thus obtained contained a high level of impurities. Hence it was essential to proceed to further purification steps on extracts to minimize chromatographic interferences and ions suppression. Silica [5,18] and diol-silica gel columns [2,19] were generally used to purify the peptaibols (fungal cultures). In this study, the sediment extracts were purified on diol-silica gel and alamethicin F50 was eluted by fractions C and D (dichloromethane/ethanol 90:10 and 50:50 v/v, respectively). Because of partial dissolution of the extract in dichloromethane, it was necessary to optimize the deposit mode. Thus, two different procedures were tested: mode 1 - solubilization of the extract in three successive solvent mixtures; mode 2 - dry deposit.

The recovery of alamethicin F50 was not significantly different depending on modes 1 and 2 as shown in Fig. 1a (Mann-Whitney, p-value $=0.042$ ). However, there were significantly fewer impurities eluted when using mode 2 than when eluted with mode 1 , as shown in Fig. 1b (Mann-Whitney, p-value $=0.05$ ). Moreover, repeatability was better with mode 2 than with mode 1 . The dry deposit mode (mode 2) was therefore chosen for the purification of sediment extracts because of less interference from impurities and better repeatability.

\section{FIGURE 1}

\subsection{LC/MS identification of peptaibols}

Analysed under neutral conditions and positive mode by ESI-IT-MS, long-sequence peptaibols mainly appeared as doubly charged sodium adduct ions $[\mathrm{M}+2 \mathrm{Na}]^{2+}$ with a peptidic isotopic profile (Fig. 2a). In LC/MS, their detection was performed through three scan events repeated throughout the chromatographic separation: a total current ion scan (fullscan) from $\mathrm{m} / \mathrm{z} 150$ to 2000 and two enhanced resolution scans (zoomscan) from $\mathrm{m} / \mathrm{z} 870$ to 890 and from $\mathrm{m} / \mathrm{z} 985$ to 1015. An additional analysis in $\mathrm{MS}^{2}$ mode was performed during a second run on the sodium adduct ions observed previously. This generated a spectrum containing mainly the $a_{n}$ and $y_{n}$ ion series as classically reported by others authors [20], while $b_{n}$ ions, predominant in the acid medium, were also detectable but in lower abundance [21,22]. Peptide identification was based on the production of $\mathrm{N}$ - and C-termini fragments resulting from preferential breaking of the Aib-Pro bond [23-25]. $\mathrm{MS}^{2}$ analysis of $\mathrm{m} / \mathrm{z} 1004.3$ (alamethicin F50/5) is depicted in Fig. $2 b$ which shows a predominant doubly charged ion $\left[\mathrm{M}-\mathrm{H}_{2} \mathrm{O}+2 \mathrm{Na}\right]^{2+}$ at $\mathrm{m} / \mathrm{z} 995.8$ corresponding to a loss of a water molecule on the amino alcohol located at the C-terminus. The N-terminus $\left[\mathrm{a}_{13}+\mathrm{Na}\right]^{+}$at $\mathrm{m} / \mathrm{z} 1183.8$ and the C-terminus $\left[\mathrm{y}_{7}+\mathrm{Na}\right]^{+}$at $\mathrm{m} / \mathrm{z}$ 796.6 could be easily identified. An Aib residue can be visualized between fragments $\left[\mathrm{a}_{12}+\mathrm{Na}\right]^{+}$at $\mathrm{m} / \mathrm{z} 1098.7$ and $\left[\mathrm{a}_{13}+\mathrm{Na}\right]^{+}$at $\mathrm{m} / \mathrm{z} 1183.8$.

\section{FIGURE 2}




\section{FIGURE 3} To investigate the matrix effect, matrix matched calibration was performed using sediment extracts spiked with the alamethicin F50 reference solution after purification (e.g. for fraction D, Fig. 3a, b, c). Both external and matrix matched calibration curves, obtained by summing the peak areas of the two alamethicin components F50/5 and F50/7, were observed to be linear up to a concentration of $100 \mu \mathrm{g} / \mathrm{L}$ with correlation coefficients higher than 0.98 . The comparison of matrix matched calibrations performed with sediments from different origins (La Rochelle and Fiers d'Ars) showed a significant and variable matrix effect with a signal decrease varying from 20 to 52 \% compared to the signal of alamethicin F50 in methanolic solution. Matrix matched calibration requires at least two LC/MS runs per analysis: one for the sample extract and one for the sample extract spiked with a known quantity of the reference peptaibol. However, it permitted the correction of signal quenching and taking into account the variability of sedimentary matrices.

The analytical method was validated considering the linear range, limit of detection (LOD) and precision. The limit of quantification (LOQ) was determined using the method of Vial and Jardy [26] with a pre-established value of area relative standard deviation (RSD) of $10 \%$. For the reference peptaibol in methanolic solutions, LOD and LOQ were respectively 0.5 and $1.7 \mu \mathrm{g} / \mathrm{L}$. For matrix matched calibration samples, the signal intensity of alamethicin F50 was decreased by coeluted substances originating from the sediments. Consequently, LOD and LOQ were increased, reaching respectively 2.5 and $8.3 \mu \mathrm{g} / \mathrm{L}$, corresponding to a detection of $250 \mathrm{pg} / \mathrm{g}$ and a quantification of $830 \mathrm{pg} / \mathrm{g}$ of sediment (ww).

Intra-day statistics of accuracy and precision were determined for matrix matched calibration method (Table 2). The accuracy, expressed in terms of bias (deviation from true values) was between $29 \%$ for the lowest concentration (below LOQ), and $2 \%$ for a concentration of $9.4 \mathrm{ng} / \mathrm{g}$ of sediment. The precision, given by relative standard deviations, was from $10 \%$ for a concentration of $0.6 \mathrm{ng} / \mathrm{g}$ to $2 \%$ for a concentration of $9.4 \mathrm{ng} / \mathrm{g}$.

The whole procedure, from sample treatment to instrumental quantification, provided a satisfactorily accurate result with a recovery of $86 \pm 4 \%$ determined using spiked sediment samples at a concentration of $10 \mathrm{ng} / \mathrm{g}$ (Fig. 1a). 
The method developed (acetone/acetic acid extraction; dry deposit; LC/MS analysis using three scan events; matrix matched calibration) was applied to natural sediment samples collected from different sites along the French Atlantic coast. Long-sequence peptaibols were identified and quantified in samples collected from Fier d'Ars but they were not observed in sediment samples collected from the Bay of Marennes-Oléron, Auray River and the Bay of Veys.

In the Fier d'Ars samples, after chromatographic separation, four doubly charged ions with a peptidic isotopic profile were observed at $m / z$ 991.2, 991.7, 998.2 and 998.7 (e.g. for $\mathrm{m} / \mathrm{z}$ 991.7, Fig. 4a, b). The molecular masses and retention times of these compounds are shown in Table 3. To confirm their peptaibolic nature, $\mathrm{MS}^{2}$ fragmentation was carried out. Fragmentation profiles were obtained for the two main ions $\mathrm{m} / \mathrm{z} 991.7$ and 998.7 and were similar in both cases to the fragmentation pattern of long-sequence peptaibols (e.g. for $\mathrm{m} / \mathrm{z}$ 991.7, Fig. 4c). An identical N-terminus fragment at $\mathrm{m} / \mathrm{z} 1163.8$ was identified for these two peptaibols. Two different C-termini parts were observed, respectively, at $\mathrm{m} / \mathrm{z} 773.5$ and 787.5 . Peptides with molecular masses of 1937.4 and $1951.4 \mathrm{u}$ and showing these $\mathrm{N}$ - and C-termini fragments showed numerous similarities with longibrachins and trichokonins, 20-residue peptaibols isolated from Trichoderma species [27-31]. The quantification of peptaibols observed in Fier d'Ars samples allowed establishing a concentration of $5.2 \pm 2.1 \mathrm{ng} / \mathrm{g}$ of sediment $(\mathrm{ww})(\mathrm{n}=2)$.

\section{FIGURE 4}

TABLE 3

\section{Conclusion}

The method described using LC/ESI-IT-MS allows both the identification of peptaibols and, for the first time, their quantification in the pg/g range in complex matrices. LOD and LOQ were respectively 250 and $830 \mathrm{pg} / \mathrm{g}$ in marine sediments. Several sediment samples were analysed to evaluate the environmental contamination and the possible implication of these fungal metabolites in toxicity episodes observed in populations of bivalves along the Atlantic coast. The presence of long-sequence peptaibols was shown in sediments collected from Fier d'Ars and trace amounts were determined in these samples. The adaptation of this analytical method to shellfish matrices is under consideration. Further investigations will permit studying the relationship between environmental concentrations and the toxicity of these compounds for marine organisms. 
Samples from the Bay of Marennes-Oléron, Auray River and the Bay of Veys were 343 collected in the framework of the French program "MOREST" coordinated by IFREMER. 344 We would like to express our thanks to C. Robiou du Pont, N. Berthet and M. Le Goff for 345 their technical participation.

346

347

348

349 
[1] C. Sallenave-Namont, Y.F. Pouchus, T. Robiou du Pont, P. Lassus, J.F. Verbist, 354 Mycopathologia 149 (2000) 21.

[2] A. Landreau, Y.F. Pouchus, J.F. Biard, C. Sallenave-Namont, T. Robiou du Pont, J.F. 356 Verbist, J. Microbiol. Meth. 48 (2002) 181.

[3] T. Degenkolb, A. Berg, W. Gams, B. Schlegel, U. Gräfe, J. Pept. Sci. 9 (2003) 666.

358

[4] J.K. Chugh, B.A. Wallace, Biochem. Soc. Trans. 29 (2001) 565.

359

[5]

S. Oh, B. Yun, S. Lee, J. Kim, I. Yoo, J. Antibiot. 55 (2002) 557.

360

[6] S. Rebuffat, C. Goulard, B. Bodo, M.F. Roquebert, Recent Res. Devel. Org. Bioorg. 361

[7] B.S. Yun, I.D. Yoo, Y.H. Kim, Y.S. Kim, S.J. Lee, K.S. Kim, W.H. Yeo, Tetrahedron 363

[8] M. Schiell, J. Hofmann, M. Kurz, F.R. Schmidt, L. Vértesy, M. Vogel, J. Wink, G. Seibert, J. Antibiot. 54 (2001) 220.

[9] C. Sallenave-Namont, Y.F. Pouchus, M. Bardouil, P. Lassus, M.F. Roquebert, J.F. Verbist, Toxicon 37 (1999) 77.

[10] L. Poirier, M. Montagu, A. Landreau, M. Mohammed-Benkada, O. Grovel, C. Sallenave-Namont, J. Biard, C. Amiard-Triquet, J.C. Amiard, Y.F. Pouchus, Chem. Biodivers. (2007) in press.

[11] C. Amiard-Triquet, O. Geffard, A. Geffard, H. Budzinski, J.C. Amiard, D. Fichet, H. Pouliquen, Y. Berthelot, E. His, in H. Tremblay, J. Locat, R. Galvez-Cloutier (Editors), Contaminated Sediments: Characterization, Evaluation, Mitigation/Restoration, Univ. Laval, Québec, 2003, p. 349.

[12] M. Schirmbock, M. Lorito, Y.L. Wang, C.K. Hayes, I. Arisan-Atac, F. Scala, G.E. Harman, C.P. Kubicek, Appl. Environ. Microbiol. 60 (1994) 4364.

[13] A. Psurek, C. Neusü $\beta$, T. Degenkolb, H. Brückner, E. Balaguer, D. Imhof, G.K.E. Scriba, J. Pept. Sci. 12 (2006) 279.

[14] A. Szekeres, B. Leitgeb, L. Kredics, Z. Antal, L. Hatvani, L. Manczinger, C. Vagvölgyi, Acta Microbiol. Immunol. 52 (2005) 137.

[15] J. Kirschbaum, C. Krause, R.K. Winzheimer, H. Brückner, J. Pept. Sci. 9 (2003) 799.

[16] J. Peltola, A. Ritieni, R. Mikkola, P.A. Grigoriev, G. Pocsfalvi, M.A. Andersson, M.S. Salkinoja-Salonen, Appl. Environ. Microbiol. 70 (2004) 4996.

[17] A. Iida, M. Sanekata, T. Fujita, H. Tanaka, A. Enoky, G. Fuse, M. Kanai, P. Rudewicz, E. Tachikawa, Chem. Pharm. Bull. 42 (1994) 1070.

[18] S. Rebuffat, C. Goulard, S. Hlimi, B. Bodo, J. Pept. Sci. 6 (2000) 519.

[19] M. Mohamed-Benkada, M. Montagu, J.F. Biard, F. Mondeguer, P. Vérité, M. Dalgalarrondo, J. Bissett, Y.F. Pouchus, Rapid Commun. Mass Spectrom. 20 (2006) 1176.

[20] V. Sabareesh, P. Balaram, Rapid Commun. Mass Spectrom. 20 (2006) 618. 
391 [21] P. Roepstorff, J. Fohlman, Biomed. Mass Spectrom. 11 (1984) 601.

392 [22] K. Biemann, Biomed. Environ. Mass Spectrom. 16 (1988) 99.

393 [23] M. Przybylski, I. Dietrich, I. Manz, H. Brückner, Biomed. Mass Spectrom. 11 (1984) 394569.

395 [24] H. Brückner, W.A. Konig, M. Aydin, G. Jung, Biochim. Biophys. Acta 827 (1985) 51.

396 [25] A. Jaworski, H. Brückner, J. Chromatogr. A 862 (1999) 179.

397 [26] J. Vial, A. Jardy, Anal. Chem. 71 (1999) 2672.

398 [27] L. Whitmore, J.K. Chugh, C.F. Snook, B.A. Wallace, J. Pept. Sci. 9 (2003) 663.

399 [28] Q. Huang, Y. Tezuka, Y. Hatanaka, T. Kikuchi, A. Nishi, K. Tubaki, Chem. Pharm. 400 Bull. 43 (1995) 1663.

401 [29] Q. Huang, Y. Tezuka, Y. Hatanaka, T. Kikuchi, A. Nishi, K. Tubaki, Chem. Pharm. 402 Bull. 44 (1996) 590.

403 [30] G. Leclerc, S. Rebuffat, C. Goulard, B. Bodo, J. Antibiot. 51 (1998) 170.

404 [31] G. Leclerc, C. Goulard, Y. Prigent, B. Bodo, H. Wroblewski, S. Rebuffat, J. Nat. Prod. 405 64 (2001) 164. 
406

407

408

409

410

411

412

413

414

415

416

417

418

419

420

421

422

423

424

425

426

427

428

429

430

431

432

433

434

435

436

Figure captions

Fig. 1. Influence of the purification mode of crude extracts

Mode 1: extract deposited with three successive fractions: dichloromethane/ethanol 100:0, 90:10 and 50:50 $(\mathrm{v} / \mathrm{v})$;

Mode 2: dry deposit

(a) Cumulative recovery of alamethicin F50

(b) Cumulative percentage of eluted impurities

Fig. 2. Mass spectra of alamethicin F50/5

(a) Zoomscan mode

(b) $\mathrm{MS}^{2}$ spectrum of ion at $\mathrm{m} / \mathrm{z} 1004.3[\mathrm{M}+2 \mathrm{Na}]^{2+}$

The main fragments corresponding to $\mathrm{a}_{\mathrm{n}}$ and $\mathrm{y}_{\mathrm{n}}$ ion series are shown.

Fig. 3. LC/ESI-IT-MS analysis of surface sediment samples collected from Fiers d'Ars chromatograms of fraction D spiked with alamethicin F50 reference solution ( $25 \mu \mathrm{g} / \mathrm{L})$

(a) Total ion current

(b) Detection on the range [1003.9-1004.9]: peak of alamethicin F50/5

(c) Detection on the range [1010.9-1011.9]: peak of alamethicin F50/7

Fig. 4. LC/ESI-IT-MS analysis of surface sediment samples collected from Fiers d'Ars

(a) Chromatogram (detection on the range [991.2-992.2])

(b) Mass spectrum corresponding to peak at $t_{R}=6.11 \mathrm{~min}$

(c) $\mathrm{MS}^{2}$ spectrum of ion at $\mathrm{m} / \mathrm{z} 991.7[\mathrm{M}+2 \mathrm{Na}]^{2+}$

The main fragments corresponding to $\mathrm{a}_{\mathrm{n}}$ and $\mathrm{y}_{\mathrm{n}}$ ion series are shown. 
(a)

Cumulative recovery of

alamethicins (\%)

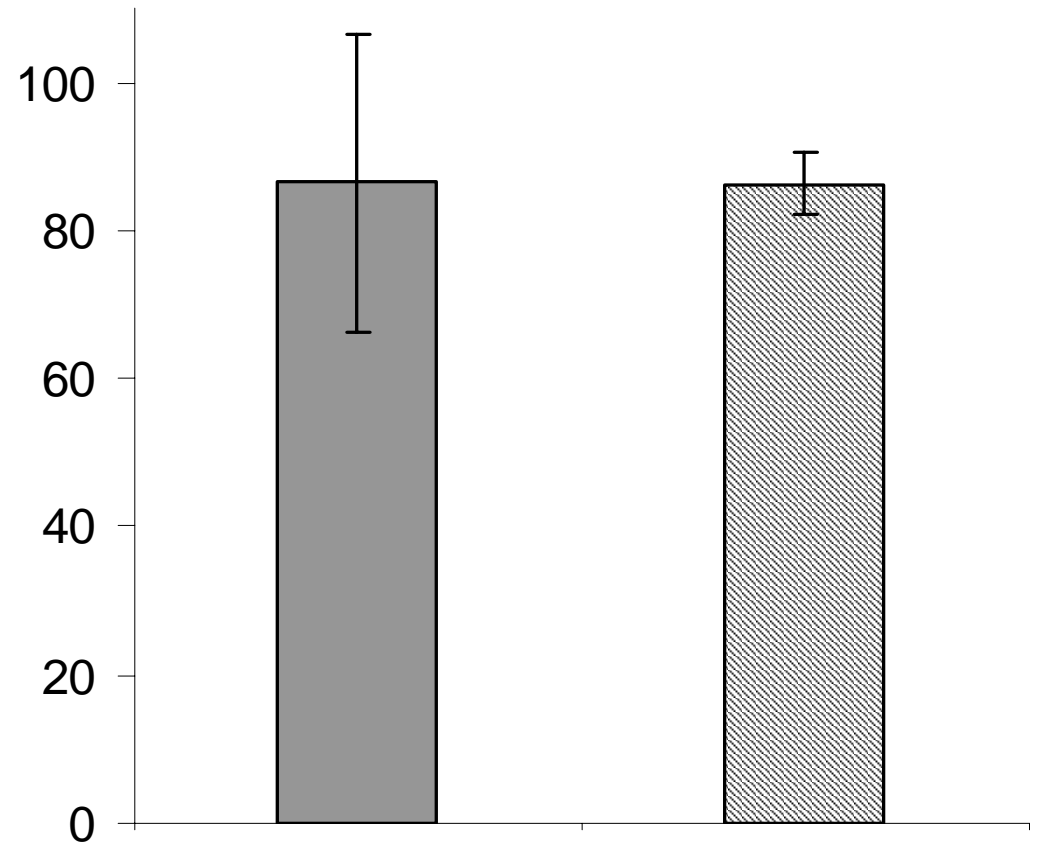

Mode 1 (b)

Cumulative percentage of eluted impurities (\%)

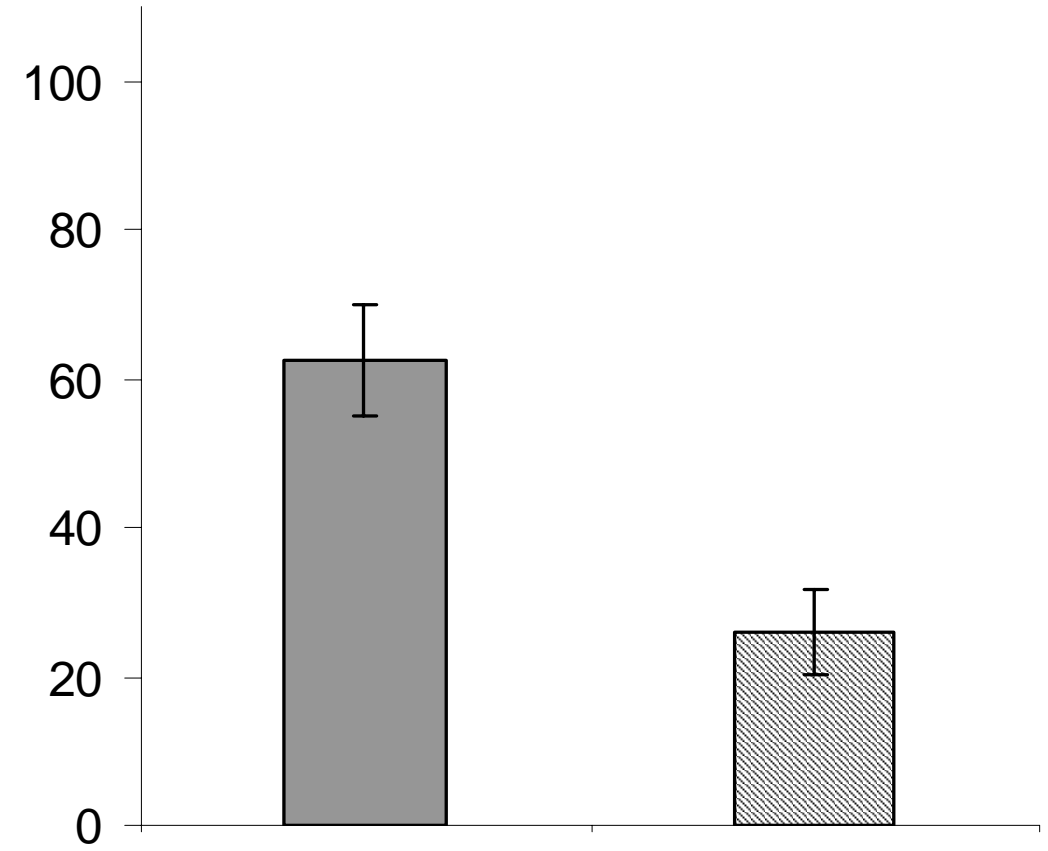

Mode 1
Mode 2 


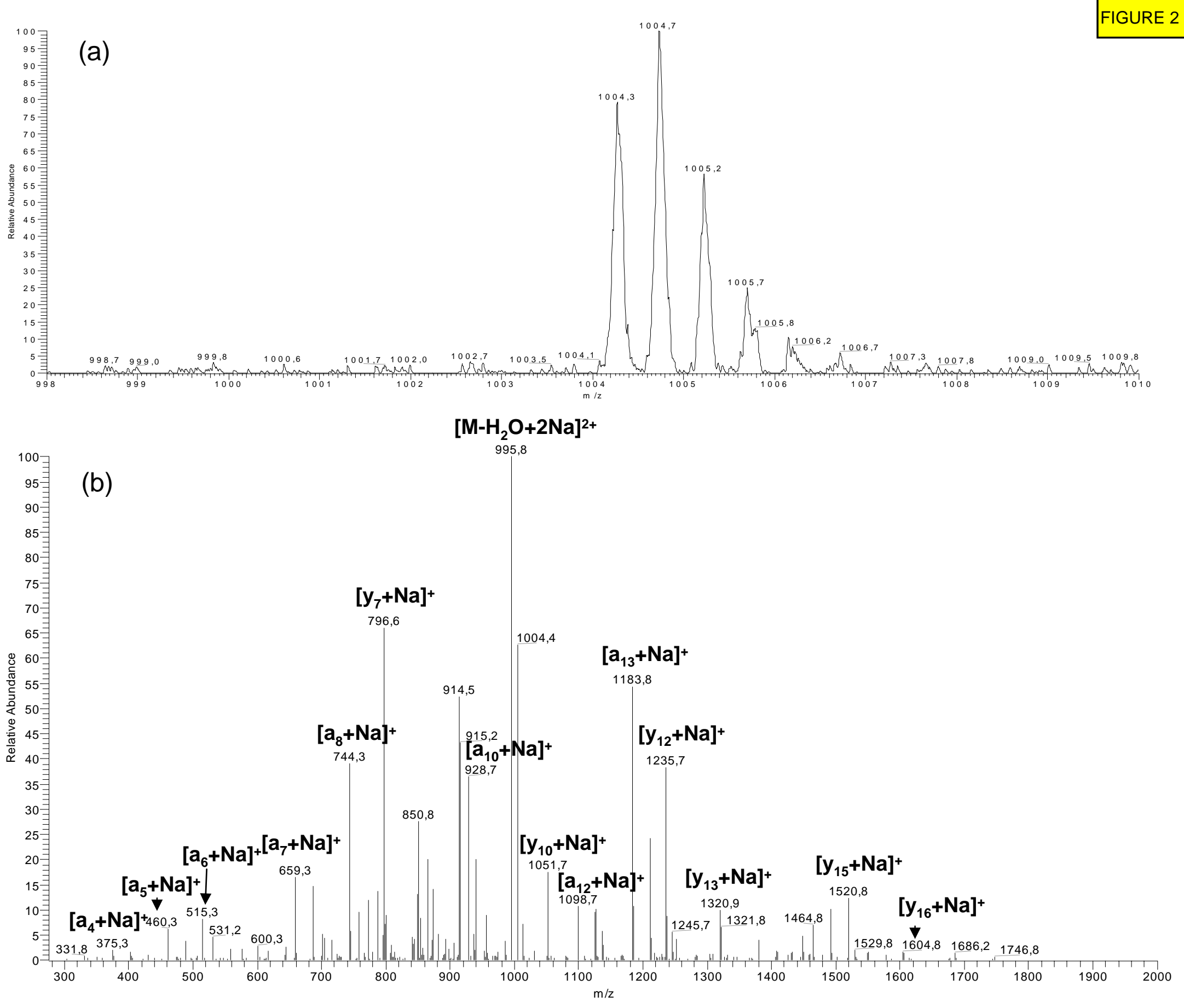




\section{FIGURE 3}

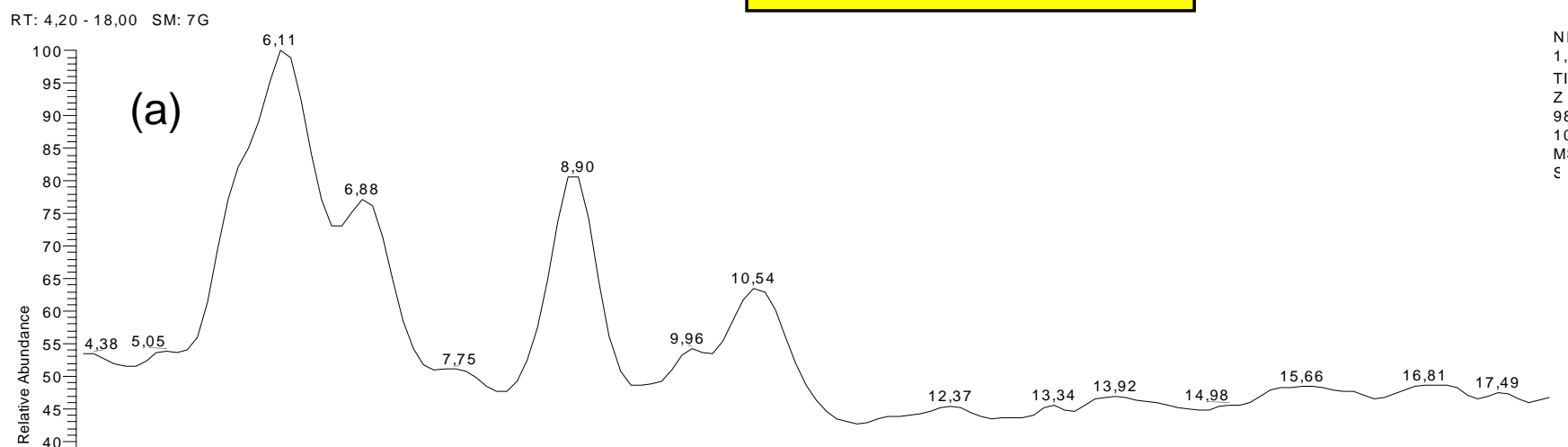

NL:
$1,70 E 7$

TIC F: + ESI

Z ms [

$015,00]$

MS
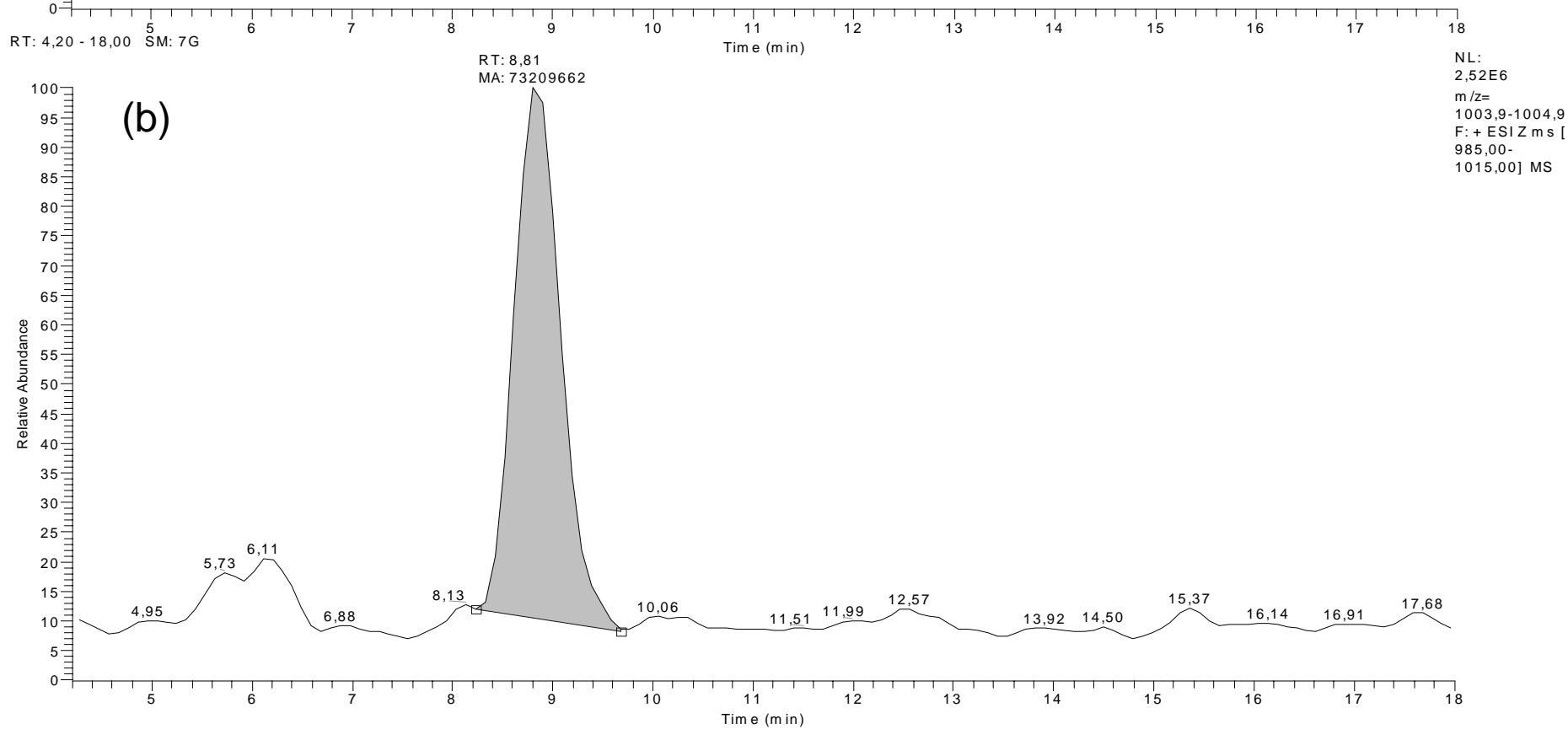

RT: 4,20-18,00 SM 7B

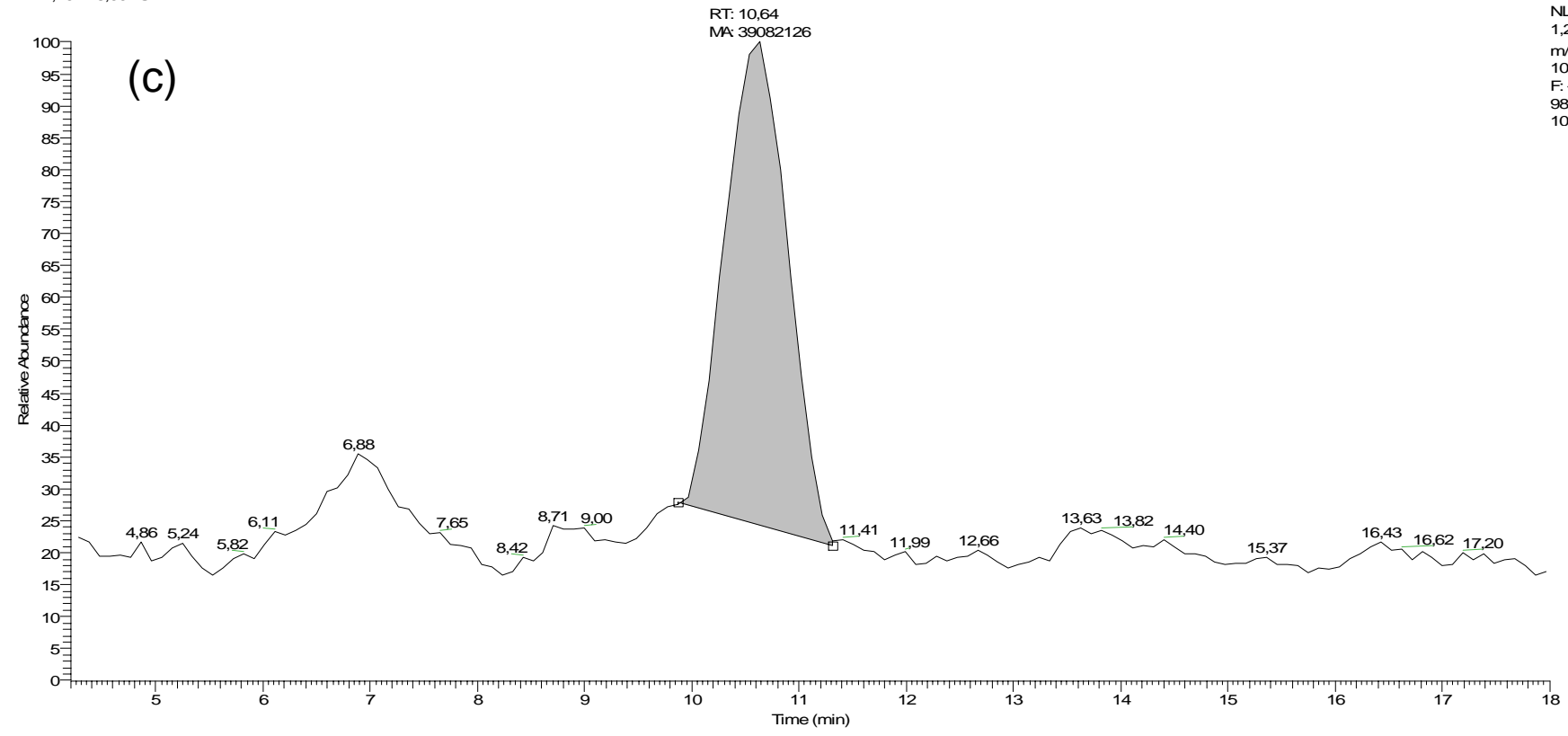

NL:

$\mathrm{m} / \mathrm{z}=$

F: + ESI Zms [ 985,00 -

$15.001 \mathrm{MS}$ 


\section{FIGURE 4}

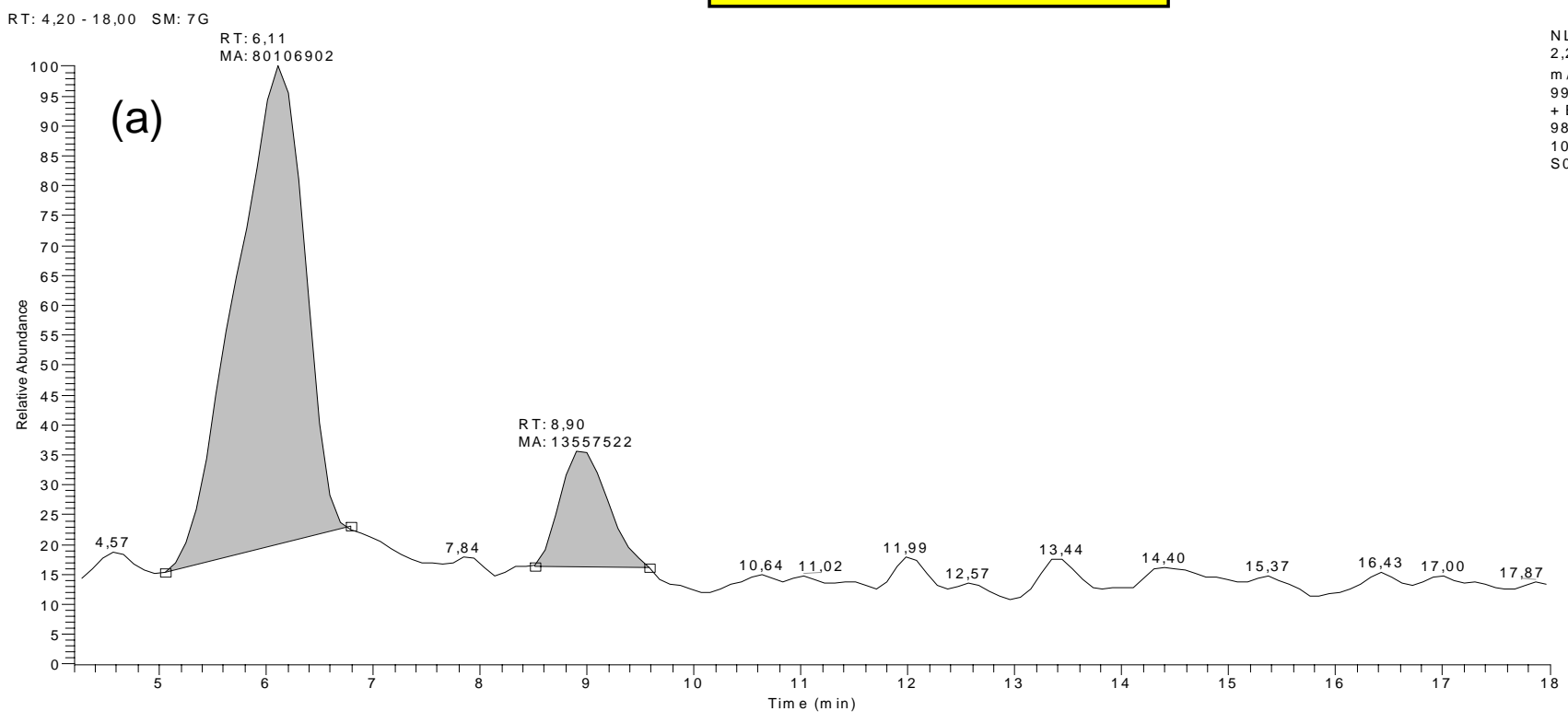

T: + ESIZ ms [ 985,00-1015,00]
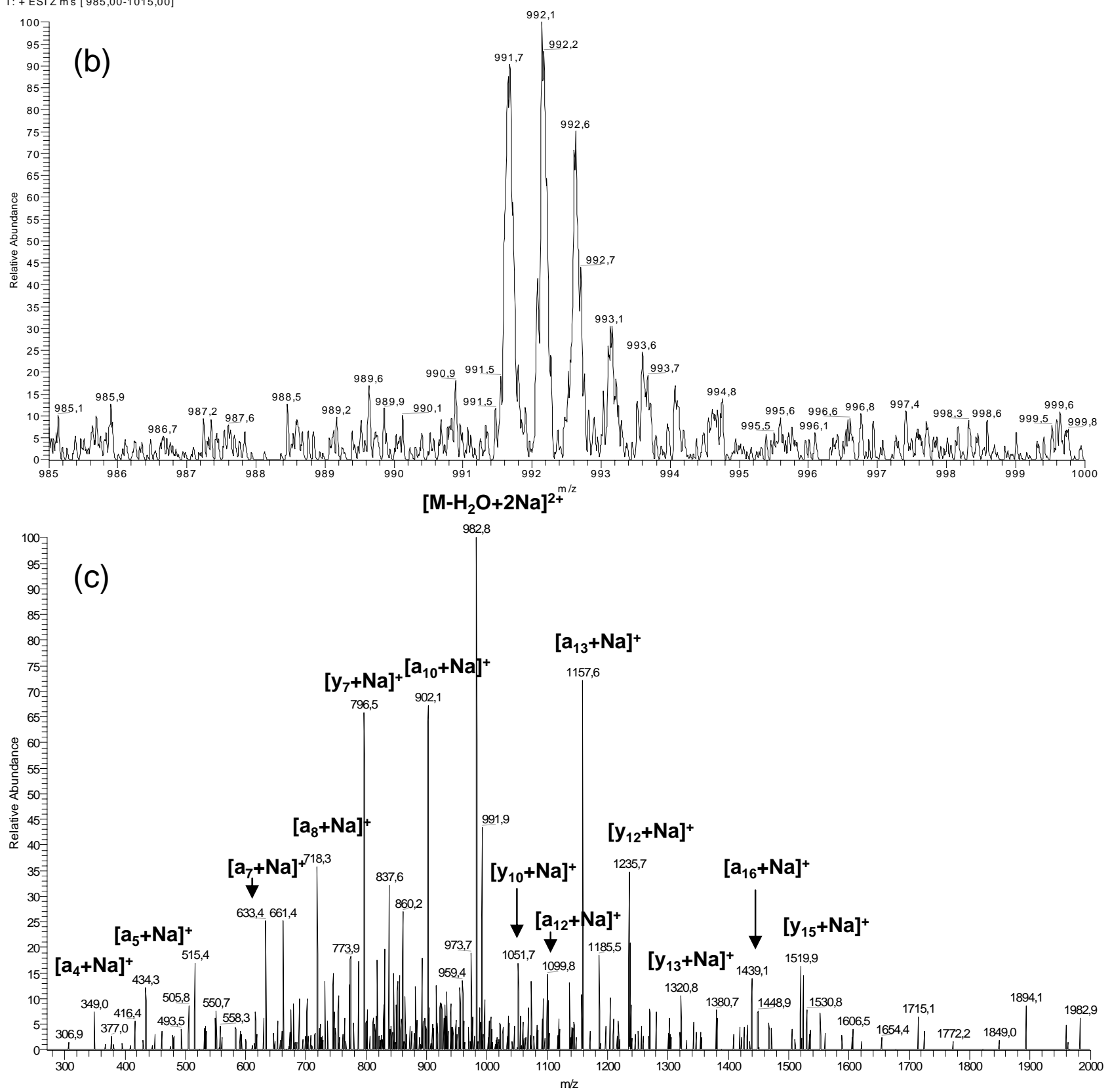


\section{TABLES}

2

\section{Table 1}

Influence of the solvent mixture on alamethicin F50 extraction from sediments spiked at 10 ng/g.

\begin{tabular}{lc}
\hline \multicolumn{1}{c}{ Tested solvents } & $\begin{array}{c}\text { Mean recovery (\%) } \\
\pm \text { SD (n=3) }\end{array}$ \\
\hline a: dichloromethane / methanol (1:1, v/v) & $8.7 \pm 0.0$ \\
b: methanol / TFA (0.1\%, v/v) & $1.9 \pm 0.0$ \\
c: ethanol / acetic acid (1\%, v/v) & $5.8 \pm 0.0$ \\
d: acetone / acetic acid (1\%, v/v) & $86 \pm 20$ \\
e: acetone / hydrochloric acid $(0.02 \%, \mathrm{v} / \mathrm{v})$ & $64 \pm 9.0$ \\
\hline
\end{tabular}

8

9

10

11 
Table 2

13 Matrix matched calibration: repeatability and accuracy.

14

15

\begin{tabular}{cccc}
\hline $\begin{array}{c}\text { Alamethicin } \\
\begin{array}{c}\text { Theoretical (ng/g of } \\
\text { sediment) }\end{array}\end{array}$ & $\begin{array}{c}\text { Mean (ng/g of } \\
\text { sediment) } \\
\pm \text { SD (n=6) }\end{array}$ & RSD (\%) & Bias (\%) \\
\hline 0.6 & $0.8 \pm 0.1$ & 10 & 29 \\
1.2 & $1.1 \pm 0.1$ & 7 & -8 \\
2.3 & $2.2 \pm 0.2$ & 9 & -4 \\
4.7 & $3.8 \pm 0.2$ & 4 & -18 \\
9.4 & $9.5 \pm 0.2$ & 2 & 2 \\
\hline
\end{tabular}

16

17

18 
19 Table 3

20 Spectral and chromatographic characteristics of peptaibols observed in surface sediment 21 samples from Fier d'Ars

22

23

\begin{tabular}{ccc}
\hline $\begin{array}{c}\text { Observed ions } \\
{[\mathrm{M}+2 \mathrm{Na}]^{2+}(\mathrm{m} / \mathrm{z})}\end{array}$ & Calculated M (u) & $\mathrm{t}_{\mathrm{R}}(\mathrm{min})$ \\
\hline 991.2 & 1936.4 & 8.90 \\
991.7 & 1937.4 & 6.11 \\
998.2 & 1950.4 & 10.06 \\
998.7 & 1951.4 & 6.98 \\
\hline
\end{tabular}

24 